\title{
The COVID-19 Lockdown and CPAP Adherence: The More Vulnerable Ones Less Likely to Improve Adherence?
}

\author{
Sijana Demirovic $\mathbb{D}^{1,2}$ \\ Linda Lusic Kalcina (iD) ${ }^{1,2}$ \\ Ivana Pavlinac Dodig (iD) ${ }^{1,2}$ \\ Renata Pecotic (ID) ${ }^{1,2}$ \\ Maja Valic $(\mathbb{D})^{1,2}$ \\ Natalija Ivkovic (iD ${ }^{2}$ \\ Zoran Dogas (D) ${ }^{1,2}$
}

'Department of Neuroscience, University of Split School of Medicine, Split, Croatia; ${ }^{2}$ Split Sleep Medicine Center, University Hospital Center Split, Split, Croatia
Correspondence: Zoran Dogas Department of Neuroscience, University of Split School of Medicine, Soltanska 2, Split, 21000, Croatia

Tel + 38521557858

$\mathrm{Fax}+38521557955$

Email zoran.dogas@mefst.hr
Purpose: Due to the possible interplay of factors predisposing to severe COVID-19 outcomes and negative health consequences of poorly controlled OSA, adherence to continuous positive airway pressure (CPAP) therapy among OSA patients might be crucial during COVID-19 pandemics. Lockdown-related changes in CPAP adherence were investigated in CPAP users willing to participate in this study. Pre-lockdown adherence, age, gender, comorbidities and anxiety were analyzed as predictors of COVID-19 lockdown adherence.

Patients and Methods: A cross-sectional study performed at Split Sleep Medicine Center included 101 severe OSA patients (78.2\% male). CPAP memory cards were assessed during 6 months of pre-lockdown and 40 days of lockdown (March/April 2020) period. A total of 81 patients in pre-lockdown met good CPAP adherence criteria ( $\geq 4$ hours/night on $70 \%$ nights). Results: CPAP adherence improved during COVID-19 lockdown in the total sample of severe OSA patients. The percentage of adherent nights and CPAP usage hours per night increased during lockdown in good pre-lockdown CPAP adherers $(\mathrm{p}=0.011$ and $\mathrm{p}=0.001$, respectively), women ( $\mathrm{p}=0.003$ and $\mathrm{p}=0.001$, respectively) and respondents younger than 58 years ( $\mathrm{p}=0.007$ and $\mathrm{p}<0.001$, respectively). Out of 20/101 poor pre-lockdown CPAP adherers, 9 have shifted to good lockdown adherence. When comorbidities, BMI and anxiety were taken into account, older and male respondents were recognized as less likely to improve CPAP usage hours during lockdown $\left(\mathrm{R}^{2}=9.4 \% ; \mathrm{p}=0.032\right)$.

Conclusion: The lockdown-related CPAP adherence improved in severe OSA patients, with a shift in almost half of poor pre-lockdown adherers towards good lockdown CPAP adherence. Women, younger and good pre-lockdown CPAP adherers were more adherent during lockdown. Despite being vulnerable groups for both OSA and COVID-19, no expected adherence improvements were observed in men and older patients.

Keywords: OSA, CPAP, CPAP adherence, COVID-19, lockdown

\section{Plain Language Summary}

Recent findings suggested an intertwined relationship of factors predisposing to severe COVID-19 outcomes and insufficiently treated obstructive sleep apnea (OSA). Therefore, adherence to continuous positive airway pressure (CPAP) therapy among OSA patients might be crucial when confronting the current infectious outbreak. We aimed to investigate changes in CPAP adherence during the COVID-19 lockdown, taking into account pre-lockdown adherence, age, gender, comorbidities and anxiety, as well as to investigate predictors of lockdown-related adherence. This study included 101 severe OSA patients, whose CPAP memory cards were assessed during 6 months of pre-lockdown and 40 days of lockdown (March/April 2020) period. The adherence assessment included the percentage of adherent 
nights (nights when CPAP was used for $\geq 4$ hours/night) and averaged hours of CPAP usage per night in the pre-lockdown and lockdown period. CPAP usage for $\geq 4$ hours/night on at least $70 \%$ of nights was used as a criterion for patients' classifications into two groups, good and poor adherers. CPAP adherence improved during COVID-19 lockdown in the studied sample of CPAP users, with a shift in almost half of poor pre-lockdown respondents towards good lockdown CPAP adherence. Women, younger and good pre-lockdown CPAP adherers were more adherent during lockdown. Despite being vulnerable groups for both OSA and COVID-19, male and older CPAP users were less likely to improve lockdown CPAP usage. A personalized approach in line with precision medicine focused on improving CPAP adherence, aimed at men and older respondents as vulnerable groups, might reduce the COVID-19 health burden in severe OSA patients.

\section{Introduction}

Due to the challenges imposed by the novel coronavirus disease 2019 (COVID-19), sleep medicine services were substantially reduced with underwhelming obstructive sleep apnea (OSA) management opportunities across Europe. ${ }^{1}$ Considering that OSA is a global health burden often remaining undiagnosed, the number of OSA patients among COVID-19 cases might be greater than acknowledged. ${ }^{1,2}$ Novel findings have indeed yielded an increased risk for severe COVID-19 forms and outcomes in OSA patients. ${ }^{3-5}$ Recent studies on COVID-19 patients with adverse outcomes revealed male gender, advanced age, obesity and underlying cardiovascular, metabolic and chronic respiratory conditions as risk factors, ${ }^{2,6,7}$ indicating an overlap between COVID-19 vulnerable and OSA population groups. ${ }^{1}$

Having in mind the possible intertwined relationship of factors predisposing to severe COVID-19 outcomes and negative health consequences of insufficiently treated OSA, ${ }^{6-10}$ effective continuous positive airway pressure (CPAP) therapy might be of particular interest when confronting the infectious outbreak. ${ }^{1,2}$ Specifically, it has been shown that increased hours of CPAP usage led to a greater reduction of cardiovascular morbidity and mortality. 9,11,12 However, beneficial therapeutic responses are constrained by patients' impaired adherence, whose association with the lack of self-efficacy and disease-related risk perception has been most consistent. ${ }^{13}$

Certain guidelines suggested a plausible risk for CPAPinduced aerosolization, supporting CPAP cessation among OSA patients during COVID-19 pandemic. ${ }^{14}$ Taking into consideration the risk uncertainty and harm-benefit assessment, other clinical guidelines encouraged CPAP therapy continuation, ${ }^{15}$ proposing CPAP as promising respiratory support in COVID-19 patients with respiratory failure. ${ }^{16}$ Given the widespread recognition of suboptimal adherence to CPAP, ${ }^{13}$ the ambiguous recommendations for CPAP management during lockdown might have further compromised CPAP adherence.

Recent studies revealed a common perception of severe personalized trauma during the pandemic, emerging as increased anxiety, fear, depression and posttraumatic stress symptoms. ${ }^{17}$ Furthermore, although it has been proposed that good CPAP adherence patterns established at earlier stages remain stable, ${ }^{18}$ previous research has found a decrease in CPAP adherence across numerous traumatic experiences. ${ }^{19,20}$ However, there are inconsistent results regarding CPAP adherence changes during COVID-19 lockdown, ${ }^{21-23}$ since it is difficult to study less adherent CPAP users and to recruit them as respondents in relevant studies. With this in mind, the respondents willing to participate in this study were included, with an assumption they were more adherent than overall CPAP users. Also, it is yet to be determined whether male and older patients as vulnerable population groups for both COVID-19 and OSA, ${ }^{1,6,7}$ are more prone to improve CPAP adherence. Thus, in order to provide additional information about the lockdown impact on CPAP adherence, this study aimed to investigate lockdown-related changes in CPAP adherence among severe OSA patients with regard to pre-lockdown adherence, gender, age, comorbidities and anxiety, as well as to investigate predictors of adherence during the COVID-19 lockdown. We hypothesized that CPAP adherence will improve in patients with higher risk for adverse COVID-19 outcomes, specifically in male and older CPAP adherers.

\section{Patients and Methods Design and Study Population}

Following the lift of 40 days COVID-19 lockdown in Croatia, a cross-sectional study was conducted at the Split Sleep Medicine Center (SSMC) in CPAP-treated patients, previously diagnosed with severe OSA (ApneaHypopnea Index, AHI $\geq 30$ /hour). A pilot sample of 9 patients was assessed before and during COVID-19 lockdown in order to calculate the sample size. Based on a mean difference of 0.39 and the standard deviation (SD) of differences of 1.32 , the minimum required sample 
was 100 patients when the type I and II errors were set at 0.01 , with the lockdown-related change in hours of CPAP usage as a primary endpoint.

Upon reaching a participant on the telephone, a sleep medicine trainee informed the individual about the study. If agreed to participate, the patients were invited to SSMC for CPAP adherence assessment and asked to complete a purpose-built questionnaire, as well as the State-Trait Anxiety Inventory (STAI). Inclusion criteria were $\geq 18$ years of age and $\geq 6$ months of CPAP therapy. Of 147 patients contacted, some were unreachable $(n=27)$, whereas others provided incomplete $(n=17)$ or none $(n=2)$ CPAP adherence data. The final sample included 101 participants (Figure 1). The study protocol was approved by the Biomedical Research Ethics Committee at the University of Split, School of Medicine (\#2181-198-03-04-14-0027). A written informed consent was obtained prior to all procedures carried out in accordance with the ethical standards established by the 1964 Helsinki declaration.

\section{Procedure and Measures}

Whole-night in-laboratory polysomnography (PSG, Alice 6LE, Philips Respironics, Eindhoven, Netherlands) or whole-night unattended polygraphy (PG, SOMNOcheck2, Weinmann, Germany) was performed prior to CPAP therapy initiation. The diagnosis of OSA was defined in accordance with the American Academy of Sleep Medicine (AASM) and European Sleep Research Society (ESRS) guidelines. ${ }^{24}$

The study questionnaire comprised three sections assessing Demographics (general information and background), COVID-19 related history (questions about COVID-19 positivity, as well as symptomatology, hospitalization and ongoing CPAP usage, if infected with COVID-19) and Self-reported CPAP adherence (hours of CPAP usage, problems while using CPAP and CPAP cleaning frequency before and during lockdown). All subjects reported to be COVID-19 negative. The duration of CPAP therapy prior to lockdown and presence of chronic diseases were obtained from medical records at SSMC.

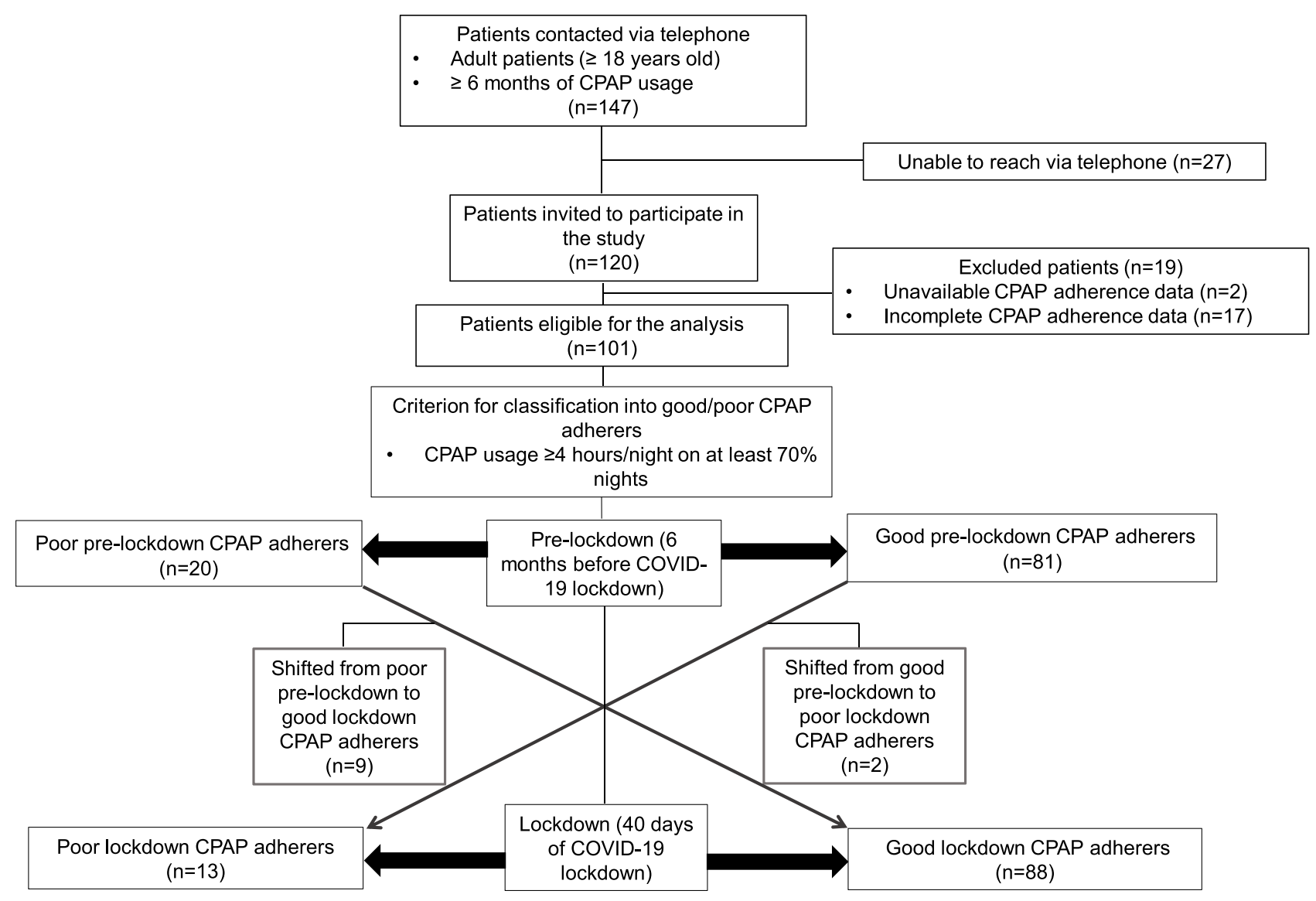

Figure I Flow chart of subject recruitment.

Abbreviation: COVID-19, coronavirus disease 2019; CPAP, continuous positive airway pressure. 
Patients' anxiety levels were evaluated using STAI, ${ }^{25}$ measuring state (STAI-S subscale) and trait (STAI-T subscale) anxiety, self-assessed on a Likert scale from 1 to 4 , including 20 questions for each subscale. The range of scores for each subscale is 20 to 80 , with higher scores indicating greater anxiety levels.

Objective adherence data from the pre-lockdown (6 months before lockdown) and lockdown period (40 days of lockdown) were assessed using CPAP memory cards. The adherence assessment included the percentage of adherent nights (nights when CPAP was used for $\geq 4$ hours/night) and averaged hours of CPAP usage per night in the pre-lockdown and lockdown period. Pooled averages of CPAP usage hours and percentages of adherent nights were analyzed.

CPAP usage for $\geq 4$ hours/night on at least $70 \%$ of nights ${ }^{26}$ was used as a criterion for patients' classifications into two groups, good and poor adherers. Characteristics of patients who shifted from poor pre-lockdown to good lockdown CPAP adherers (improved CPAP adherence), as well as of patients who shifted from good pre-lockdown to poor lockdown adherers (impaired CPAP adherence) were described. Predictors of the lockdown-related change in CPAP usage hours per night were investigated to identify respondents less likely to improve CPAP usage during lockdown. The lockdown-related change in CPAP usage hours was calculated as the difference between CPAP usage hours during and before lockdown.

\section{Statistical Analysis}

Results were presented as median and interquartile range (IQR) for non-normally distributed data or ordinal scale data, and as mean $\pm \mathrm{SD}$ for normally distributed data or close to normally distributed data following normality test and visual inspection of data distribution. Parametric assessment of group differences was performed using $t$-test for paired samples. Linear regression was performed using the change in hours of CPAP usage per night during lockdown as a dependent variable in the regression model. Dichotomous variables included in linear regression were gender (0-female, 1-male), body mass index (BMI, 0-BMI $\leq 32.5 \mathrm{~kg} / \mathrm{m}^{2}, 1$-BMI $\left.>32.5 \mathrm{~kg} / \mathrm{m}^{2}\right)$, arterial hypertension (AH) and diabetes mellitus type 2 (DM2), both coded as $0-$ no, 1-yes. Significance was set at $\mathrm{p}<0.05$.

\section{Results}

The study sample included predominantly men $(78.2 \%)$, with the median age of 58 (IQR 50-69) years.
Demographic, clinical and objective pre-lockdown CPAP adherence data are summarized in Table 1 .

\section{Lockdown CPAP Adherence: Subjective/ Objective}

There were no significant changes in self-reported prelockdown and lockdown CPAP usage, regarding the hours of CPAP usage per night (from $6.73 \pm 1.40$ hours to $6.73 \pm 1.57$ hours, $p>0.999$ ). However, there were significant changes in the objective assessment. The percentage of adherent nights increased during lockdown in the total sample of severe OSA patients (from $84.72 \pm 18.25 \%$ to $87.60 \pm 20.16 \%, \mathrm{p}=0.004)$. In addition, there was an increase in hours of CPAP usage per night during lockdown (from $6.12 \pm 1.83$ hours to $6.45 \pm 1.96$ hours, $\mathrm{p}<0.001$ )

\section{Lockdown CPAP Adherence: Patients' Characteristics}

The median age of the total sample was used as a cut-off value to classify respondents into younger and older than 58 years. The percentage of adherent nights, as well as hours of CPAP usage per night, increased during lockdown

Table I Demographic, Clinical and Pre-Lockdown CPAP Adherence Data of the Respondents $(n=101)$

\begin{tabular}{|l|c|}
\hline \multicolumn{2}{|l|}{ Demographic Data } \\
\hline Male/female ratio & $3.6: 1$ \\
Age (years) & $58(50-69)$ \\
BMI (kg/m²) & $33.0 \pm 5.38$ \\
Current smoking & $15(15.2)$ \\
\hline Clinical Data & $52.79 \pm 19.88$ \\
\hline AHI before CPAP usage (events/hour) & $2.85 \pm 2.87$ \\
Residual AHI (events/hour) & $2(1-5)$ \\
CPAP usage before lockdown (years) & $51(51.0)$ \\
AH & $18(18.2)$ \\
DM2 & $10(10.0)$ \\
Depression & $37(30.5-44)$ \\
STAl-T score & $6.73 \pm 1.40$ \\
\hline Pre-Lockdown CPAP Adherence Data & $84.73 \pm 18.25$ \\
\hline Self-reported CPAP usage per night (hours) & $6.12 \pm 1.83$ \\
\hline Nights when CPAP was used for $\geq 4$ hours (\%) &
\end{tabular}

Note: Data is presented as mean \pm standard deviation, $\mathrm{n}(\%)$ or median (interquartile range).

Abbreviations: $\mathrm{AH}$, arterial hypertension; $\mathrm{AHI}$, apnea-hypopnea index; $\mathrm{BMI}$, body mass index; CPAP, continuous positive airway pressure; DM2, diabetes mellitus type 2; Lockdown, 40 days of lockdown; Pre-lockdown, 6 months before lockdown; STAI, state-trait anxiety inventory; STAI-T, trait anxiety subscale. 
Table 2 Pre-Lockdown and Lockdown CPAP Usage Data with Regard to Age, Gender, BMI, Comorbidities and STAI-T Score

\begin{tabular}{|c|c|c|c|c|c|c|c|}
\hline & & \multicolumn{3}{|c|}{$\begin{array}{l}\text { Nights When CPAP Was Used for } \geq 4 \text { Hours/ } \\
\text { Night (\%) }\end{array}$} & \multicolumn{3}{|c|}{ CPAP Usage per Night (Hours) } \\
\hline & & Pre-Lockdown & Lockdown & p-value ${ }^{a}$ & Pre-Lockdown & Lockdown & $p$-value ${ }^{a}$ \\
\hline Total sample & & $84.72 \pm 18.25$ & $87.60 \pm 20.16$ & 0.004 & $6.12 \pm 1.83$ & $6.45 \pm 1.96$ & $<0.001$ \\
\hline Age (years) ${ }^{b}$ & $\begin{array}{l}\text { Younger } \leq 58 \text { years }(n=51) \\
\text { Older }>58 \text { years }(n=50)\end{array}$ & $\begin{array}{l}86.45 \pm 15.35 \\
82.87 \pm 20.65\end{array}$ & $\begin{array}{l}90.57 \pm 15.58 \\
84.82 \pm 23.66\end{array}$ & $\begin{array}{l}0.007 \\
0.195\end{array}$ & $\begin{array}{l}6.11 \pm 1.56 \\
6.16 \pm 2.08\end{array}$ & $\begin{array}{l}6.59 \pm 1.70 \\
6.32 \pm 2.19\end{array}$ & $\begin{array}{c}<0.001 \\
0.220\end{array}$ \\
\hline Gender & $\begin{array}{c}\text { Male }(n=79) \\
\text { Female }(n=22)\end{array}$ & $\begin{array}{l}84.77 \pm 18.84 \\
84.36 \pm 15.89\end{array}$ & $\begin{array}{l}86.76 \pm 21.53 \\
91.20 \pm 13.62\end{array}$ & $\begin{array}{l}0.095 \\
0.003\end{array}$ & $\begin{array}{l}6.14 \pm 1.89 \\
6.10 \pm 1.61\end{array}$ & $\begin{array}{l}6.36 \pm 2.06 \\
6.80 \pm 1.53\end{array}$ & $\begin{array}{l}0.024 \\
0.001\end{array}$ \\
\hline BMI $\left(\mathrm{kg} / \mathrm{m}^{2}\right)^{\mathrm{c}}$ & $\begin{array}{l}\text { BMI } \leq 32.5 \mathrm{~kg} / \mathrm{m}^{2} \quad(n=52) \\
\text { BMI }>32.5 \mathrm{~kg} / \mathrm{m}^{2}(n=48)\end{array}$ & $\begin{array}{l}82.70 \pm 18.25 \\
86.51 \pm 18.10\end{array}$ & $\begin{array}{l}87.01 \pm 19.74 \\
88.22 \pm 20.80\end{array}$ & $\begin{array}{l}0.006 \\
0.233\end{array}$ & $\begin{array}{l}5.93 \pm 1.97 \\
6.28 \pm 1.61\end{array}$ & $\begin{array}{l}6.35 \pm 2.04 \\
6.52 \pm 1.86\end{array}$ & $\begin{array}{l}0.001 \\
0.062\end{array}$ \\
\hline $\mathrm{AH}$ (yes/no) & $\begin{array}{l}\text { Yes }(n=5 I) \\
\text { No }(n=49)\end{array}$ & $\begin{array}{l}82.73 \pm 20.32 \\
87.52 \pm 14.56\end{array}$ & $\begin{array}{l}86.16 \pm 22.52 \\
90.07 \pm 16.7 \mid\end{array}$ & $\begin{array}{l}0.040 \\
0.060\end{array}$ & $\begin{array}{l}6.00 \pm 1.89 \\
6.33 \pm 1.72\end{array}$ & $\begin{array}{l}6.24 \pm 1.93 \\
6.75 \pm 1.92\end{array}$ & $\begin{array}{l}0.078 \\
<0.001\end{array}$ \\
\hline DM2 (yes/no) & $\begin{array}{l}\text { Yes }(n=\mid 8) \\
\text { No }(n=8 \mid)\end{array}$ & $\begin{array}{l}83.58 \pm 20.50 \\
85.66 \pm 17.23\end{array}$ & $\begin{array}{l}86.25 \pm 22.38 \\
88.43 \pm 19.54\end{array}$ & $\begin{array}{l}0.267 \\
0.019\end{array}$ & $\begin{array}{l}6.06 \pm 2.17 \\
6.21 \pm 1.73\end{array}$ & $\begin{array}{l}6.57 \pm 1.99 \\
6.49 \pm 1.94\end{array}$ & $\begin{array}{l}0.043 \\
0.004\end{array}$ \\
\hline STAI-T score ${ }^{d}$ & $\begin{array}{l}\text { STAI-T score } \leq 37(n=56) \\
\text { STAI-T score }>37(n=44)\end{array}$ & $\begin{array}{l}81.90 \pm 19.96 \\
88.51 \pm 15.12\end{array}$ & $\begin{array}{l}85.26 \pm 23.93 \\
90.68 \pm 13.72\end{array}$ & $\begin{array}{l}0.024 \\
0.143\end{array}$ & $\begin{array}{l}5.88 \pm 1.95 \\
6.49 \pm 1.61\end{array}$ & $\begin{array}{l}6.18 \pm 2.19 \\
6.83 \pm 1.59\end{array}$ & $\begin{array}{l}0.021 \\
0.007\end{array}$ \\
\hline
\end{tabular}

Notes: Data is presented as mean \pm standard deviation, unless otherwise stated; ${ }^{\mathrm{a}}$ t-test for paired samples; ${ }^{\mathrm{b}}$ Median age of the total sample was 58 (IQR $\left.50-69\right)$ and used as a cut-off value; 'Median BMI of the total sample was 32.5 (IQR 29.7-36) and used as a cut-off value; 'Median STAI-T score was 37 (IQR 30.5-44) and used as a cut-off value. Abbreviations: $\mathrm{AH}$, arterial hypertension; BMI, body mass index; CPAP, continuous positive airway pressure; DM2, diabetes mellitus type 2; IQR, interquartile range; Lockdown, 40 days of lockdown; Pre-lockdown, 6 months before lockdown; STAI, state-trait anxiety inventory; STAI-T, trait anxiety subscale.

in respondents younger than 58 years (from $86.45 \pm 15.35 \%$ to $90.57 \pm 15.58 \%, \mathrm{p}=0.007$ and from $6.11 \pm 1.56$ hours to $6.59 \pm 1.70$ hours, $\mathrm{p}<0.001$, respectively, Table 2). There were no significant changes in the percentage of adherent nights and hours of CPAP usage per night during lockdown in respondents older than 58 years (Table 2).

The percentage of adherent nights and hours of CPAP usage per night improved during lockdown among female respondents (from $84.36 \pm 15.89 \%$ to $91.20 \pm 13.62 \%$, $\mathrm{p}=0.003$ and from $6.10 \pm 1.61$ hours to $6.80 \pm 1.53$ hours, $\mathrm{p}=0.001$, respectively), whilst only improved hours of CPAP usage per night were observed in male respondents (from $6.14 \pm 1.89$ hours to $6.36 \pm 2.06$ hours, $\mathrm{p}=0.024$, Table 2). There were no significant differences regarding demographic, clinical and objective pre-lockdown CPAP adherence data between male and female respondents.

Based on the median BMI of the total sample, respondents were additionally classified into two groups: BMI $\leq 32.5 \mathrm{~kg} / \mathrm{m}^{2}$ and BMI $>32.5 \mathrm{~kg} / \mathrm{m}^{2}$. The percentage of adherent nights and hours of CPAP usage per night increased during lockdown in respondents with BMI $\leq 32.5 \mathrm{~kg} / \mathrm{m}^{2}$ (from $82.70 \pm 18.25 \%$ to $87.01 \pm 19.74 \%$, $\mathrm{p}=0.006$ and from $5.93 \pm 1.97$ hours to $6.35 \pm 2.04$ hours, $\mathrm{p}=0.001$, respectively, Table 2 ). There were no significant changes in CPAP usage before and during lockdown in those with BMI $>32.5 \mathrm{~kg} / \mathrm{m}^{2}$ (Table 2).

An increase in hours of CPAP usage per night was evident during lockdown in non-hypertensive respondents (from $6.33 \pm 1.72$ hours to $6.75 \pm 1.92$ hours, $\mathrm{p}<0.001$, Table 2), whereas an increase in the percentage of adherent nights was found among hypertensive respondents (from $82.73 \pm 20.32 \%$ to $86.16 \pm 22.52 \%, p=0.040$, Table 2 ). In addition, both the percentage of adherent nights and hours of CPAP usage per night during lockdown (from 85.66 $\pm 17.23 \%$ to $88.43 \pm 19.54 \%, \mathrm{p}=0.019$ and from $6.21 \pm 1.73$ hours to $6.49 \pm 1.94$ hours, $\mathrm{p}=0.004$, respectively, Table 2) were increased in respondents without DM2. However, only an increase in CPAP usage hours during lockdown was found in respondents with DM2 (from 6.06 \pm 2.17 hours to 6.57 \pm 1.99 hours, $\mathrm{p}=0.043$, Table 2).

The median score on the STAI-T subscale (STAI-T score) in our sample was 37 , which according to Croatian percentile norms indicates that males express anxiety in the 63rd to 68th percentile, whereas females in the 61 st to 76 th percentile. $^{25}$ The median STAI-T score was used as a cut-off value for distinguishing respondents with the STAI-T score $\leq 37$ (less anxious) and $>37$ (more anxious). An increase in percentage of adherent nights, as 
well as in hours of CPAP usage per night during lockdown (from $81.90 \pm 19.96 \%$ to $85.26 \pm 23.93 \%, \mathrm{p}=0.024$ and from $5.88 \pm 1.95$ hours to $6.18 \pm 2.19$ hours, $\mathrm{p}=0.021$, respectively, Table 2) was evident in less anxious respondents, whereas only hours of CPAP usage per night during lockdown (from 6.49 \pm 1.61 hours to $6.83 \pm 1.59$ hours, $\mathrm{p}=0.007$, Table 2) were improved in more anxious respondents.

\section{CPAP Adherence: Lockdown vs Pre-Lockdown}

The percentage of adherent nights and hours of CPAP usage per night increased during lockdown in good pre-lockdown CPAP adherers (from $92.20 \pm 8.06 \%$ to $94.35 \pm 8.55 \%$, $\mathrm{p}=0.011$, Figure $2 \mathrm{~A}$ and from $6.79 \pm 1.28$ hours to 7.09 \pm 1.28 hours, $\mathrm{p}=0.001$, Figure $2 \mathrm{~B}$, respectively), whereas no significant improvements in CPAP usage were observed in poor pre-lockdown adherers during lockdown (from 54.23 $\pm 15.67 \%$ to $60.91 \pm 29.57 \%, \mathrm{p}=0.114$, and from $3.47 \pm 1.13$ hours to $3.90 \pm 2.16$ hours, $\mathrm{p}=0.137$, respectively).

In the pre-lockdown period, there were 81 good and 20 poor adherers, whereas in the lockdown period there were 88 good and 13 poor adherers (Figure 1). During the prelockdown, 12 out of 20 poor pre-lockdown adherers have not met any of CPAP adherence criteria, whereas 8 respondents used CPAP for $\geq 4$ hours, however, on less than $70 \%$ of nights (Table 3). Furthermore, 9 out of 20 poor pre-lockdown CPAP adherers have shifted to good lockdown CPAP adherers (Table 3). The detailed profile of respondents who shifted from poor towards good adherence during lockdown and vice versa is presented in Table 4.

\section{Predictors of Lockdown CPAP Adherence}

When a linear regression analysis was performed, in which comorbidities, BMI and level of anxiety were taken into account, male and older severe OSA patients $(\beta=-0.250$; $p=0.018$ and $\beta=-0.281 ; p=0.008$, respectively) were recognized as less likely to improve CPAP usage hours per night during lockdown $\left(\mathrm{R}^{2}=9.4 \% ; \mathrm{p}=0.032\right.$, Table 5).

\section{Discussion}

CPAP adherence improved during COVID-19 lockdown in participants included in our study. Adherence improvements during lockdown were pronounced in good prelockdown adherers, women, respondents younger than 58 years, with a BMI $\leq 32.5 \mathrm{~kg} / \mathrm{m}^{2}$, without DM2 and less anxious respondents. Furthermore, adherence

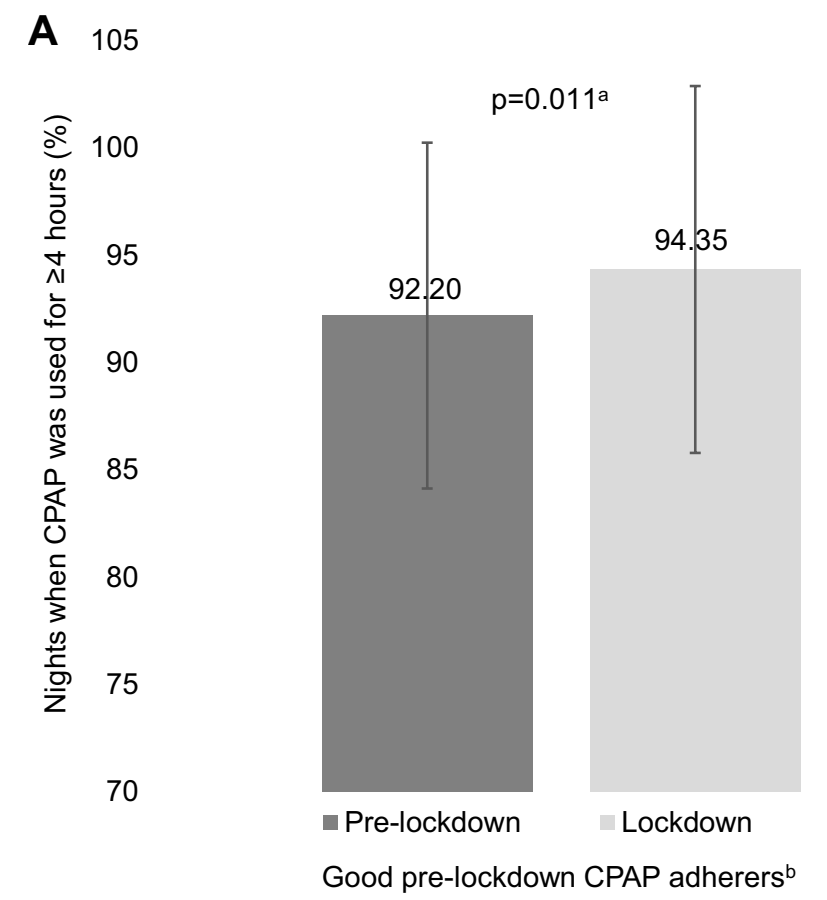

B

8.5
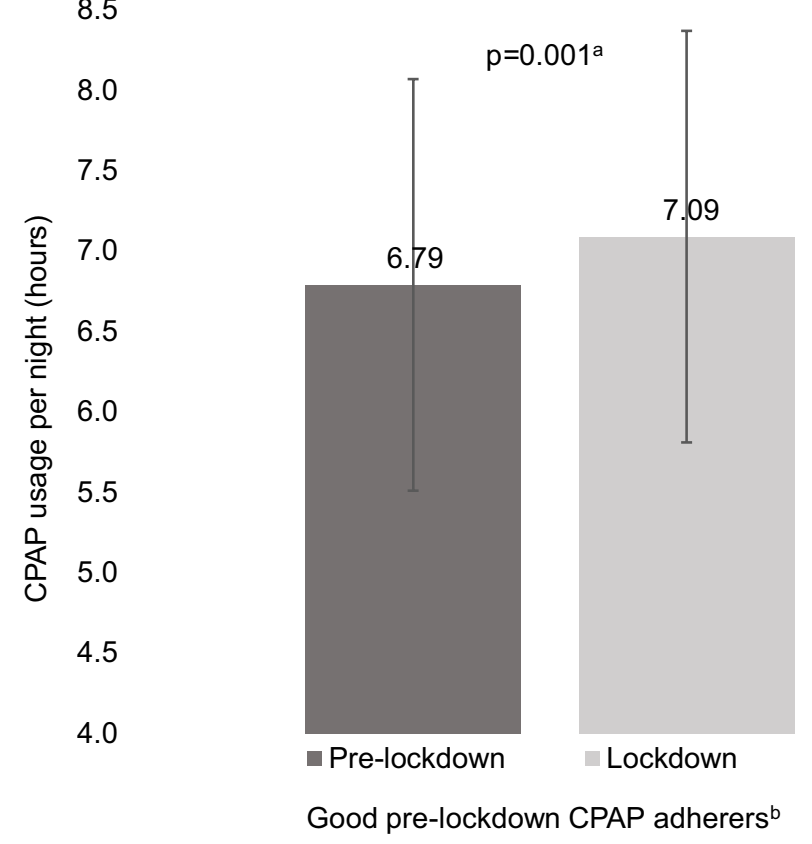

Figure 2 The average pre-lockdown (6 months before lockdown) and lockdown (40 days of lockdown) (A) percentage of adherent nights (nights when CPAP was used for $\geq 4$ hours/night) and (B) hours of CPAP usage per night in good pre-lockdown CPAP adherers $(n=8 \mathrm{I})$.

Notes: ${ }^{a}$ t-test for paired samples; ${ }^{b}$ Good CPAP adherence was defined as CPAP usage for $\geq 4 \mathrm{~h} / \mathrm{night}$ on $70 \%$ nights in the pre-lockdown period.

Abbreviation: CPAP, continuous positive airway pressure. 
Table 3 Poor CPAP Adherers During the Pre-Lockdown Period and Their Change in Adherence During the COVID-19 Lockdown ${ }^{\mathrm{a}}$

\begin{tabular}{|c|c|c|c|c|}
\hline \multirow[t]{2}{*}{$\begin{array}{l}\text { Respondents } \\
(n=20)\end{array}$} & \multicolumn{2}{|c|}{$\begin{array}{l}\text { Poor Pre-Lockdown Adherence } \\
\qquad(\mathrm{n}=20)\end{array}$} & \multicolumn{2}{|c|}{$\begin{array}{l}\text { Adherence Shifted from Poor Pre-Lockdown } \\
\text { Towards Good Lockdown } \\
\qquad(\mathrm{n}=9 / 20)\end{array}$} \\
\hline & $\begin{array}{c}\text { Nights When CPAP Was } \\
\text { Used for } \geq 4 \text { Hours/Night (\%) } \\
\text { (Criterion Met) }\end{array}$ & $\begin{array}{l}\text { CPAP Usage } \\
\text { per Night } \\
\text { (Hours) } \\
\text { (Criterion Met) }\end{array}$ & $\begin{array}{l}\text { Nights when CPAP Was } \\
\text { Used for } \geq 4 \text { Hours/Night (\%) } \\
\text { (Criterion Met) }\end{array}$ & $\begin{array}{l}\text { CPAP Usage } \\
\text { per Night } \\
\text { (Hours) } \\
\text { (Criterion Met) }\end{array}$ \\
\hline I & $8.3(-)$ & $1.40(-)$ & $0.0(-)$ & $0.39(-)$ \\
\hline 2 & $32.2(-)$ & $2.4 \mid(-)$ & $6.7(-)$ & $0.33(-)$ \\
\hline 3 & $33.9(-)$ & $2.19(-)$ & $22.5(-)$ & $1.33(-)$ \\
\hline 4 & $41.5(-)$ & $3.58(-)$ & $25.0(-)$ & $2.69(-)$ \\
\hline 5 & $44.9(-)$ & $3.17(-)$ & $52.5(-)$ & $3.03(-)$ \\
\hline 6 & $45.9(-)$ & $3.48(-)$ & $75.0(+)$ & $5.73(+)$ \\
\hline 7 & $53.0(-)$ & $1.67(-)$ & $53.0(-)$ & $2.53(-)$ \\
\hline 8 & $54.1(-)$ & $4.25(+)$ & $45.0(-)$ & $3.82(-)$ \\
\hline 9 & $58.5(-)$ & $4.04(+)$ & $82.5(+)$ & $5.38(+)$ \\
\hline 10 & $59.0(-)$ & $3.89(-)$ & $62.5(-)$ & $4.63(+)$ \\
\hline II & $61.2(-)$ & $2.43(-)$ & $42.9(-)$ & $2.00(-)$ \\
\hline 12 & $61.2(-)$ & $3.77(-)$ & $85.0(+)$ & $4.97(+)$ \\
\hline 13 & $64.0(-)$ & $2.28(-)$ & $64.0(-)$ & $2.58(-)$ \\
\hline 14 & $64.5(-)$ & $4.03(+)$ & $92.5(+)$ & $5.72(+)$ \\
\hline 15 & $65.0(-)$ & $4.45(+)$ & $82.5(+)$ & $5.78(+)$ \\
\hline 16 & $66.0(-)$ & $2.82(-)$ & $66.0(-)$ & I.88 (-) \\
\hline 17 & $66.3(-)$ & $5.35(+)$ & $100.0(+)$ & $7.75(+)$ \\
\hline 18 & $67.2(-)$ & $5.10(+)$ & $97.5(+)$ & $7.30(+)$ \\
\hline 19 & $68.9(-)$ & $4.82(+)$ & $78.0(+)$ & $5.38(+)$ \\
\hline 20 & $68.9(-)$ & $4.20(+)$ & $85.0(+)$ & $4.82(+)$ \\
\hline $\begin{array}{l}\text { Total number of respondents } \\
\text { with the met criterion }(+)\end{array}$ & $0(+)$ & $8(+)$ & $9(+)$ & $10(+)$ \\
\hline $\begin{array}{l}\text { Total number of respondents } \\
\text { with both criteria met }(+,+)\end{array}$ & \multicolumn{2}{|l|}{$0(+,+)$} & \multicolumn{2}{|l|}{$9(+,+)$} \\
\hline
\end{tabular}

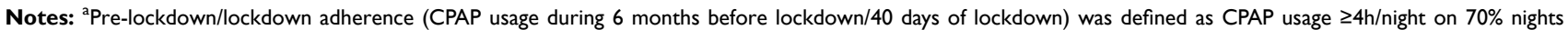
before/during lockdown, which was the criterion for classification into poor and good pre-lockdown/lockdown adherers. ${ }^{b}$ During pre-lockdown 12 respondents have not met any of CPAP adherence criteria, whereas 8 respondents used CPAP for $\geq 4$ hours, however, on less than $70 \%$ of nights.

Abbreviations: COVID-19, coronavirus disease 20I9; CPAP, continuous positive airway pressure; Pre-lockdown, 6 months before lockdown; Lockdown, 40 days of lockdown.

improvements were evident in both respondents, with and without arterial hypertension. Out of 20 poor pre-lockdown CPAP adherers, 9 have shifted to good lockdown CPAP adherers. In contrast to our hypothesis, when comorbidities, BMI and anxiety were taken into account, older and male respondents were less likely to further improve hours of CPAP usage per night during lockdown. The latter finding identified men and older respondents as vulnerable groups of CPAP adherers during the COVID-19 lockdown.

The well-known dose-response relationship between hours of CPAP usage and positive health outcomes ${ }^{13}$ might be particularly compromised by the underestimated importance of CPAP usage during lockdown. In this regard, poorly controlled OSA could be observed as a superimposing factor to the extensively addressed high risk for adverse COVID-19 outcomes in men and older population. ${ }^{6,7}$ Strikingly, even the global recognition of COVID-19 as a threat to the respiratory system has not encouraged the identified groups of OSA patients to reinforce CPAP adherence, in order to protect their already compromised respiratory function. ${ }^{21,27}$

Regardless of so far inconclusive evidence on genderrelated differences in adhering to CPAP treatment, ${ }^{28,29}$ our results indicated a more pronounced adherence improvement during lockdown among females. These differences 
Table 4 The Profile of Respondents Who Shifted from Poor PreLockdown to Good Lockdown CPAP Adherers $(n=9)$ and from Good Pre-Lockdown to Poor Lockdown CPAP Adherers $(n=2)^{a}$

\begin{tabular}{|c|c|c|}
\hline & $\begin{array}{l}\text { Improved CPAP } \\
\text { Adherence } \\
\text { (Adherence Shifted } \\
\text { from Poor Pre- } \\
\text { Lockdown Towards } \\
\text { Good Lockdown) } \\
(n=9)\end{array}$ & $\begin{array}{l}\text { Impaired CPAP } \\
\text { Adherence } \\
\text { (Adherence Shifted } \\
\text { from Good Pre- } \\
\text { Lockdown Towards } \\
\text { Poor Lockdown) } \\
(n=2)\end{array}$ \\
\hline \multicolumn{3}{|c|}{ Demographic data } \\
\hline Male & 7 (77.8) & $2(100)$ \\
\hline Age (years) & $52(44-62)$ & $48(46-50)$ \\
\hline BMI $\left(\mathrm{kg} / \mathrm{m}^{2}\right)$ & $32.5(28.7-33.7)$ & $27.9(27.8-27.9)$ \\
\hline Current smoking & $2(22.2)$ & I $(50.0)$ \\
\hline \multicolumn{3}{|l|}{ Clinical data } \\
\hline $\begin{array}{l}\text { AHI before CPAP } \\
\text { usage (events/ } \\
\text { hour) } \\
\text { AH } \\
\text { DM2 } \\
\text { Depression } \\
\text { STAI-T score }\end{array}$ & $\begin{array}{c}6(66.7) \\
1(11.1) \\
1(11.1) \\
34(31-34)\end{array}$ & $\begin{array}{c}0(0) \\
0(0) \\
I(50.0) \\
38(34-37)\end{array}$ \\
\hline \multicolumn{3}{|c|}{ Pre-lockdown CPAP adherence data } \\
\hline $\begin{array}{l}\text { Self-reported } \\
\text { CPAP usage per } \\
\text { night (hours) }\end{array}$ & $6.0(6.0-7.0)$ & $7.5(7.3-7.8)$ \\
\hline $\begin{array}{l}\text { Nights when } \\
\text { CPAP was used } \\
\text { for } \geq 4 \text { hours/ } \\
\text { night (\%) }\end{array}$ & $65.0(61.0-67.2)$ & $80.1(75.3-84.8)$ \\
\hline $\begin{array}{l}\text { CPAP usage per } \\
\text { night (hours) }\end{array}$ & $4.2(4.0-4.8)$ & $6.0(5.5-6.4)$ \\
\hline
\end{tabular}

Notes: Data is presented as $\mathrm{n}(\%)$ or median (interquartile range), unless otherwise stated; a Pre-lockdown/lockdown adherence (CPAP usage during 6 months before lockdown/40 days of lockdown) was defined as CPAP usage $\geq 4 \mathrm{~h} /$ night on $70 \%$ nights before/during lockdown, which was the criterion for classification into poor and good pre-lockdown/lockdown adherers.

Abbreviations: $\mathrm{AH}$, arterial hypertension; $\mathrm{AHI}$, apnea-hypopnea index; $\mathrm{BMI}$, body mass index; CPAP, continuous positive airway pressure; DM2, diabetes mellitus type 2; Lockdown, 40 days of lockdown; Pre-lockdown, 6 months before lockdown; STAI, state-trait anxiety inventory; STAI-T, trait anxiety subscale.

in CPAP adherence might have arisen from the previously reported higher health-care utilization among women with OSA, based on a greater health awareness when compared to men. ${ }^{30}$ Moreover, a specific vulnerability to more severe psychological distress during quarantine has been found in females $^{31}$ and the drive to adhere might be attributable to the fear of hospitalization. ${ }^{21}$ Recent findings on higher restriction compliance during lockdown in women added to the impression that women are more willing to follow not only a prescribed treatment but overall health- and self-care recommendations. ${ }^{32}$

Greater adherence improvements have also been revealed among CPAP-treated patients without DM2 in the current study, whereas both respondents with and without AH exhibited adherence improvements. Previous findings indicated that OSA might increase the blood pressure through renin-angiotensin-aldosterone system (RAAS) stimulation. ${ }^{33}$ Following the identification of angiotensin converting enzyme 2 as the coronavirus host protein and its consequent dysfunction in degrading angiotensin II, the main RAAS effector, ${ }^{34}$ clinical concerns regarding the synergistic effect of OSA- and COVID-19-related pathways for hypertension have been raised. ${ }^{35}$ Moreover, a recent study of COVID-19 patients with DM2 including OSA-treated patients demonstrated an independent association of OSA with the risk of death. ${ }^{5}$ Despite the reports on obesity as an independent risk factor for invasive mechanical ventilation among COVID-19 patients, ${ }^{36}$ there were no changes in the CPAP usage during lockdown in obese patients in the present study. It has been outlined that the co-presence of OSA, obesity and COVID-19 might trigger the cytokine storm in patients with pneumonia and worsen respiratory disturbances through an increased inflammatory state. ${ }^{2,37}$

The lockdown-related adherence improvement among good pre-lockdown CPAP adherers in our study suggested stability of a good CPAP user even in the lockdown setting. Although the latter finding is in line with the proposed association of an early stage establishment of adherence with the long-term adherence, ${ }^{18}$ it should be highlighted that a lockdown-related shift from poor towards good CPAP adherence was observed in almost half of poor pre-lockdown CPAP adherers. Possible cornerstones of the improved CPAP use need to be identified, as well as strategies avoiding the reversal of improved adherence in the short- and long-term lockdown aftermath.

Even though our study results indicated a greater improvement in lockdown CPAP usage among less anxious respondents, which is in accordance with previous findings on the negative impact of anxiety, depression and posttraumatic stress disorder on CPAP adherence, ${ }^{19,38}$ a certain increase in lockdown CPAP usage was also evident in more anxious respondents. When linear regression was performed, age and gender effects on CPAP adherence were independent of anxiety levels in our 
Table 5 Predictors of the Lockdown-Related Change in Hours of CPAP Usage per Night

\begin{tabular}{|c|c|c|c|c|c|}
\hline & $\begin{array}{c}\text { Adjusted } \\
R^{2}\end{array}$ & \multirow[t]{2}{*}{ B } & \multirow[t]{2}{*}{ p-value } & \multirow[t]{2}{*}{$\beta$} & \multirow[t]{2}{*}{ Cl $(95 \%$ for B $)$} \\
\hline & $9.4 \%$ & & & & \\
\hline Age & & -0.020 & 0.008 & $-0.28 I$ & $-0.03-(-0.01)$ \\
\hline Gender (male) & & -0.529 & 0.018 & -0.250 & $-0.97-0.91$ \\
\hline BMI & & -0.274 & 0.140 & -0.157 & $-0.64-0.09$ \\
\hline $\mathrm{AH}$ & & -0.071 & 0.702 & -0.041 & $-0.44-0.30$ \\
\hline DM2 & & 0.302 & 0.198 & 0.135 & $-0.16-0.76$ \\
\hline Pre-lockdown hours of CPAP usage per night & & -0.025 & 0.613 & -0.051 & $-0.12-0.07$ \\
\hline STAI-S & & -0.003 & 0.824 & -0.035 & $-0.03-0.03$ \\
\hline STAI-T & & 0.009 & 0.569 & 0.093 & $-0.02-0.04$ \\
\hline
\end{tabular}

Abbreviations: $\mathrm{AH}$, arterial hypertension; $\mathrm{BMI}$, body mass index; $\mathrm{Cl}$, confidence interval; CPAP, continuous positive airway pressure; DM2, diabetes mellitus type 2; Lockdown, 40 days of lockdown; Pre-lockdown, 6 months before lockdown; STAI, state-trait anxiety inventory; STAI-S, state anxiety subscale; STAI-T, trait anxiety subscale.

study. Previous research has been focused mostly on the association of established psychological disorders with impaired CPAP adherence outside the lockdown setting, ${ }^{19,20,38}$ therefore, the relative impact of anxiety during pandemic outbreaks might be further investigated.

We acknowledge that we were only able to speculate about the influential factors in CPAP adherence changes during lockdown, due to the cross-sectional design of our study. Furthermore, although in agreement with previous adherence assessment, ${ }^{39}$ the high pre-lockdown adherence rate $(79 \%)$ in our sample introduced another limitation to this study. The possible overestimation of good CPAP adherers might be consequent to the unavailability of some patients during the research protocol, who are probably those not engaged in CPAP therapy. If our results needed to be extrapolated to non-adherent/less adherent CPAP users, their lockdown-related improvement in CPAP adherence might have been equal to our findings or even greater, due to more space for improvement. In addition, investigating less adherent CPAP users is always difficult due to the fact that their decreased motivation for therapy observed via decreased CPAP adherence is also an indicator for a lack of willingness to participate in studies like this. On the other hand, the COVID-19 pandemics may represent another factor for increased motivation in non-adherent CPAP users, which is beyond the scope of this study, but would be of special interest in future studies on vulnerable subpopulations such as male and older subjects.

Well-recognized overlapping features for OSA and COVID-19 included both male and older than 60 years of age, in addition to obesity, hypertension, diabetes mellitus and chronic obstructive pulmonary disease (COPD),${ }^{40}$ and are associated with adverse COVID-19 outcomes. Also, OSA promotes various negative effects on the cardiovascular, cerebrovascular, metabolic and immune system, ${ }^{35}$ and as such, OSA may independently increase a patient's risk for COVID-19 morbidity and mortality. ${ }^{5,41}$ However, compared to other less changeable COVID-19-related factors, OSA can be effectively managed with a well-performed CPAP therapy. ${ }^{40}$ Positive effects of CPAP in OSA patients are noticeable since the therapy onset, and the linear doseresponse relationship between CPAP and beneficial health outcomes has been widely reported. ${ }^{9,11-13,42}$ In this regard, an improved CPAP usage during the current pandemic may not only control OSA itself but also OSA-related risk for developing severe COVID-19 forms and outcomes. Taken together, adherence to CPAP as an effective OSA treatment, is of special importance during the COVID-19 pandemic. However, despite the relevance of patient's adherence to therapy in the management of OSA patients diagnosed with COVID-19, so far, only limited concern has been dedicated to this issue.

\section{Conclusion}

The average lockdown-related CPAP adherence has improved in the studied sample of CPAP users. There was also a shift in almost half of poor pre-lockdown respondents towards good lockdown CPAP adherence. However, despite the wide recognition of male gender and advanced age as risk factors for adverse COVID-19 outcomes, CPAP adherence improvements were more 
pronounced in women and younger respondents. Therefore, we believe that a personalized approach in line with precision medicine focused on improving CPAP adherence, aimed at men and older respondents as vulnerable groups, might reduce the COVID-19 health burden in severe OSA patients.

\section{Abbreviations}

$\mathrm{AH}$, arterial hypertension; AHI, apnea-hypopnea index; BMI, body mass index; $\mathrm{CI}$, confidence interval; COPD, chronic obstructive pulmonary disease; COVID-19, coronavirus disease 2019; CPAP, continuous positive airway pressure; DM2, diabetes mellitus type 2; IQR, interquartile range; Lockdown, 40 days of lockdown; OSA, obstructive sleep apnea; Pre-lockdown, 6 months before lockdown; RAAS, renin-angiotensinaldosterone system; SD, standard deviation; SSMC, Split Sleep Medicine Center; STAI, State-Trait Anxiety Inventory; STAI-S, state anxiety subscale; STAI-T, trait anxiety subscale.

\section{Data Sharing Statement}

All data and materials related to the study can be obtained by contacting the corresponding author.

\section{Ethics Approval}

Ethical standards of the institutional research committee and the 1964 Helsinki Declaration with its later amendments were applied to the protocol of the study. Ethics approval was obtained by the Ethics Committee for Biomedical Research at the University of Split School of Medicine.

\section{Consent for Publication}

Following Ethics Committee for Biomedical Research and institutional approvals at the University of Split School of Medicine, all participants were informed about the procedures and the aims of the study. A written informed consent was obtained from all patients involved, with the understanding that anonymized data could be used for research and publications.

\section{Acknowledgments}

The authors would like to thank Jelena Baricevic from the Department of Neuroscience, University of Split School of Medicine in Croatia, for technical assistance.

\section{Author Contributions}

All authors made substantial contributions to conception and design, acquisition of data, or analysis and interpretation of data; took part in drafting the article or revising it critically for important intellectual content; agreed to submit to the current journal; gave final approval of the version to be published; and agreed to be accountable for all aspects of the work.

\section{Funding}

Croatian Science Foundation (HRZZ) supported this research via grant TIHO2_SLEEP_BREATH 5935, which was obtained by Professor Zoran Dogas.

\section{Disclosure}

The authors declare they have no conflict of interest. No competing interests were reported by the authors for any financial interests or commercial associations held by the authors or their family members.

\section{References}

1. Grote L, McNicholas WT, Hedner J. Sleep apnoea management in Europe during the COVID-19 pandemic: data from the European Sleep Apnoea Database (ESADA). Eur Respir J. 2020;55 (6):2001323. doi:10.1183/13993003.01323-2020

2. Memtsoudis SG, Ivascu NS, Pryor KO, Goldstein PA. Obesity as a risk factor for poor outcome in COVID-19-induced lung injury: the potential role of undiagnosed obstructive sleep apnoea. Br J Anaesth. 2020;125 (2):e262-e263. doi:10.1016/j.bja.2020.04.078

3. Najafi A, Sadeghniiat-Haghighi K, Akbarpour S, Samadi S, Rahimi B, Alemohammad ZB. The effect of apnea management on novel coronavirus infection: a study on patients with obstructive sleep apnea. Sleep Health. 2021;7(1):14-18. doi:10.1016/j. sleh.2020.09.003

4. Maas MB, Kim M, Malkani RG, Abbott SM, Zee PC. Obstructive sleep apnea and risk of COVID-19 infection, hospitalization and respiratory failure. Sleep Breath. 2020;1-3.

5. Cariou B, Hadjadj S, Wargny M, et al. Phenotypic characteristics and prognosis of inpatients with COVID-19 and diabetes: the CORONADO study. Diabetologia. 2020;63(8):1500-1515. doi:10.1007/s00125-020-05180-x

6. Chen T, Wu D, Chen H, et al. Clinical characteristics of 113 deceased patients with coronavirus disease 2019: retrospective study. BMJ. 2020;368:m1091. doi:10.1136/bmj.m1091

7. Wang D, Hu B, Hu C, et al. Clinical characteristics of 138 hospitalized patients with 2019 novel coronavirus-infected pneumonia in Wuhan, China. JAMA. 2020;323(11):1061-1069. doi:10.1001/ jama.2020.1585

8. Marin JM, Agusti A, Villar I, et al. Association between treated and untreated obstructive sleep apnea and risk of hypertension. JAMA. 2012;307(20):2169-2176. doi:10.1001/jama.2012.3418

9. Marin JM, Carrizo SJ, Vicente E, Agusti AG. Long-term cardiovascular outcomes in men with obstructive sleep apnoea-hypopnoea with or without treatment with continuous positive airway pressure: an observational study. Lancet. 2005;365(9464):1046-1053. doi:10.1016/S0140-6736(05)71141-7

10. Kohler M, Stoewhas AC, Ayers L, et al. Effects of continuous positive airway pressure therapy withdrawal in patients with obstructive sleep apnea: a randomized controlled trial. Am J Respir Crit Care Med. 2011;184(10):1192-1199. doi:10.1164/rccm.201106-0964OC

11. Campos-Rodriguez F, Pena-Grinan N, Reyes-Nunez N, et al. Mortality in obstructive sleep apnea-hypopnea patients treated with positive airway pressure. Chest. 2005;128(2):624-633. doi:10.1378/ chest.128.2.624 
12. Barbe F, Duran-Cantolla J, Capote F, et al. Long-term effect of continuous positive airway pressure in hypertensive patients with sleep apnea. Am J Respir Crit Care Med. 2010;181(7):718-726. doi:10.1164/rccm.200901-0050OC

13. Bakker JP, Weaver TE, Parthasarathy S, Aloia MS. Adherence to CPAP: what should we be aiming for, and how can we get there? Chest. 2019;155(6):1272-1287. doi:10.1016/j.chest.2019.01.012

14. Barker J, Oyefeso O, Koeckerling D, Mudalige NL, Pan D. COVID19: community CPAP and NIV should be stopped unless medically necessary to support life. Thorax. 2020;75(5):367. doi:10.1136/thoraxjnl-2020-214890

15. Baker JG, Sovani M. Case for continuing community NIV and CPAP during the COVID-19 epidemic. Thorax. 2020;75(5):368. doi:10.1136/thoraxjnl-2020-214913

16. Nightingale R, Nwosu N, Kutubudin F, et al. Is continuous positive airway pressure (CPAP) a new standard of care for type 1 respiratory failure in COVID-19 patients? A retrospective observational study of a dedicated COVID-19 CPAP service. BMJ Open Respir Res. 2020;7 (1):e000639. doi:10.1136/bmjresp-2020-000639

17. Brooks SK, Webster RK, Smith LE, et al. The psychological impact of quarantine and how to reduce it: rapid review of the evidence. Lancet 2020;395(10227):912-920. doi:10.1016/S0140-6736(20)30460-8

18. Aloia MS, Arnedt JT, Stanchina M, Millman RP. How early in treatment is PAP adherence established? Revisiting night-to-night variability. Behav Sleep Med. 2007;5(3):229-240. doi:10.1080/ 15402000701264005

19. Collen JF, Lettieri CJ, Hoffman M. The impact of posttraumatic stress disorder on CPAP adherence in patients with obstructive sleep apnea. J Clin Sleep Med. 2012;8(6):667-672. doi:10.5664/ jcsm. 2260

20. Lettieri CJ, Williams SG, Collen JF. OSA syndrome and posttraumatic stress disorder clinical outcomes and impact of positive airway pressure therapy. Chest. 2016;149(2):483-490. doi:10.1378/chest.15-0693

21. Attias D, Pepin JL, Pathak A. Impact of COVID-19 lockdown on adherence to continuous positive airway pressure (CPAP) by obstructive sleep apnoea patients. Eur Respir J. 2020;56(1):2001607. doi:10.1183/13993003.01607-2020

22. Batool-Anwar S, Omobomi OS, Quan SF. Impact of the novel coronavirus disease on treatment adherence and sleep duration in patients with obstructive sleep apnea treated with positive airway pressure. J Clin Sleep Med. 2020;16(11):1917-1920. doi:10.5664/jcsm.8746

23. Del Campo F, Lopez G, Arroyo CA, et al. Study of the adherence to continuous positive airway pressure treatment in patients with obstructive sleep apnea syndrome in the confinement during the COVID-19 pandemic. Arch Bronconeumol. 2020;56(12):818-819. doi:10.1016/j.arbres.2020.06.019

24. Epstein LJ, Kristo D, Strollo PJ, et al. Clinical guideline for the evaluation, management and long-term care of obstructive sleep apnea in adults. J Clin Sleep Med. 2009;5(3):263-276.

25. Spielberger CD. State-Trait Anxiety Inventory (Form Y). 1st Croatian ed. Jastrebarsko: NAKLADA SLAP; 2000.

26. Schwab RJ, Badr SM, Epstein LJ, et al. An official American thoracic society statement: continuous positive airway pressure adherence tracking systems the optimal monitoring strategies and outcome measures in adults. Am J Respir Crit Care Med. 2013;188 (5):613-620. doi:10.1164/rccm.201307-1282ST
27. Eckert DJ, Malhotra A, Jordan AS. Mechanisms of apnea. Prog Cardiovasc Dis. 2009;51(4):313-323. doi:10.1016/j.pcad.2008.02.003

28. Sin DD, Mayers I, Man GC, Pawluk L. Long-term compliance rates to continuous positive airway pressure in obstructive sleep apnea: a population-based study. Chest. 2002;121(2):430-435. doi:10.1378/ chest.121.2.430

29. Pelletier-Fleury N, Rakotonanahary D, Fleury B. The age and other factors in the evaluation of compliance with nasal continuous positive airway pressure for obstructive sleep apnea syndrome. A Cox's proportional hazard analysis. Sleep Med. 2001;2(3):225-232. doi:10.1016/S1389-9457(00)00063-0

30. Greenberg-Dotan S, Reuveni H, Simon-Tuval T, Oksenberg A, Tarasiuk A. Gender differences in morbidity and health care utilization among adult obstructive sleep apnea patients. Sleep. 2007;30 (9):1173-1180. doi:10.1093/sleep/30.9.1173

31. Liu N, Zhang F, Wei C, et al. Prevalence and predictors of PTSS during COVID-19 outbreak in China hardest-hit areas: gender differences matter. Psychiatry Res. 2020;287:112921. doi:10.1016/j. psychres.2020.112921

32. Dogas Z, Lusic Kalcina L, Pavlinac Dodig I, et al. The effect of COVID-19 lockdown on lifestyle and mood in Croatian general population: a cross-sectional study. CMJ. 2020;61(4):309-318.

33. Jin ZN, Wei YX. Meta-analysis of effects of obstructive sleep apnea on the renin-angiotensin-aldosterone system. J Geriatr Cardiol. 2016;13(4):333-343. doi:10.11909/j.issn.1671-5411.2016.03.020

34. South AM, Diz DI, Chappell MC. COVID-19, ACE2, and the cardiovascular consequences. Am J Physiol Heart Circ Physiol. 2020;318 (5):H1084-H1090. doi:10.1152/ajpheart.00217.2020

35. Miller MA, Cappuccio FP. A systematic review of COVID-19 and obstructive sleep apnoea. Sleep Med Rev. 2020;55:101382. doi:10.1016/j.smrv.2020.101382

36. Simonnet A, Chetboun M, Poissy J, et al. High prevalence of obesity in severe acute respiratory syndrome coronavirus-2 (SARS-CoV-2) requiring invasive mechanical ventilation. Obesity. 2020;28 (7):1195-1199. doi:10.1002/oby.22831

37. McSharry D, Malhotra A. Potential influences of obstructive sleep apnea and obesity on COVID-19 severity. J Clin Sleep Med. 2020;16 (9):1645. doi: $10.5664 /$ jcsm. 8538

38. Kjelsberg FN, Ruud EA, Stavem K. Predictors of symptoms of anxiety and depression in obstructive sleep apnea. Sleep Med. 2005;6(4):341-346. doi:10.1016/j.sleep.2005.02.004

39. Woehrle H, Graml A, Weinreich G. Age- and gender-dependent adherence with continuous positive airway pressure therapy. Sleep Med. 2011;12(10):1034-1036. doi:10.1016/j.sleep.2011.05.008

40. Mutti C, Azzi N, Soglia M, Pollara I, Alessandrini F, Parrino L. Obstructive sleep apnea, cpap and COVID-19: a brief review. Acta Biomed. 2020;91(4):e2020196. doi:10.23750/abm.v91i4.10941

41. Peker Y, Celik Y, Arbatli S, et al. Effect of high-risk obstructive sleep apnea on clinical outcomes in adults with coronavirus disease 2019: a multicenter, prospective, observational cohort study. Ann Am Thorac Soc. 2021. doi:10.1513/AnnalsATS.202011-1409OC

42. Pecotic R, Pavlinac Dodig I, Valic M, et al. Effects of CPAP therapy on cognitive and psychomotor performances in patients with severe obstructive sleep apnea: a prospective 1-year study. Sleep Breath. 2019;23(1):41-48. doi:10.1007/s11325-018-1642-6 


\section{Publish your work in this journal}

Nature and Science of Sleep is an international, peer-reviewed, open access journal covering all aspects of sleep science and sleep medicine, including the neurophysiology and functions of sleep, the genetics of sleep, sleep and society, biological rhythms, dreaming, sleep disorders and therapy, and strategies to optimize healthy sleep.
The manuscript management system is completely online and includes a very quick and fair peer-review system, which is all easy to use. Visit http://www.dovepress.com/testimonials.php to read real quotes from published authors. 